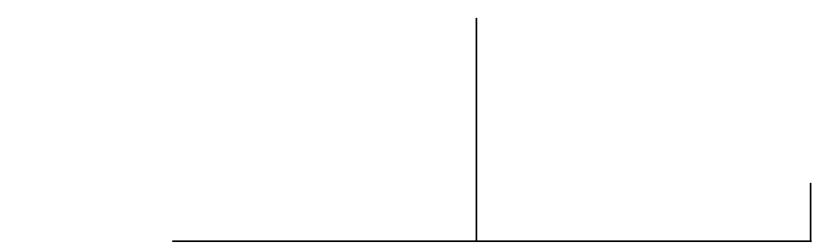

Rev. Latinoam. Psicopat. Fund., II, 3, 183-188

"Clinical trials, consensus conferences, and clinical practice”

A. Sniderman

The Lancet, vol. 345, July 24: 327-329, 1999

\title{
Estudo de The Lancet analisa as relações entre as grandes pesquisas sobre eficácia terapêutica e a prática clínica*
}

Nos últimos anos o campo das práticas clínicas tem constituído cada vez mais objeto de pesquisas sistemáticas que visam estabelecer, a partir de sólidas bases experimentais, as melhores condutas terapêuticas a serem empregadas diante de condições mórbidas específicas.

Nesse sentido, a chamada Medicina Baseada em Evidências (MBE) vem desempenhando um papel cada vez mais decisivo na delimitação da legitimidade das práticas terapêuticas, desde o ponto de vista dos resultados empiricamente demonstrados.

A escolha das condutas clínicas a serem efetivamente tomadas em um tratamento, que ao longo de toda história da medicina ocidental coube ao clínico, passa cada vez mais a ser deliberada a partir das chamadas "evidências experimentais”. Assim, assiste-se uma progressiva mudança de papéis da MBE, que passa de instrumento auxiliar nas tomadas de decisões clínicas, para o de instância reguladora da legitimidade da prática.

Cada vez mais os seguros de saúde tendem a não ressarcir os procedimentos médicos que não estejam explicitamente referendados pela MBE e os seguros contra erro médico tendem a não oferecer cobertura em situações em que o profissional optou por um método sem ampla determinação experimental de sua validade. A MBE assume, portanto, um estatuto jurídico sobre o campo da clínica. O mesmo se passa no campo estritamente mental, com

* Agradecemos a Mônica Teixeira pela indicação desse e do artigo seguinte para a seção de Resenha de Artigos. 


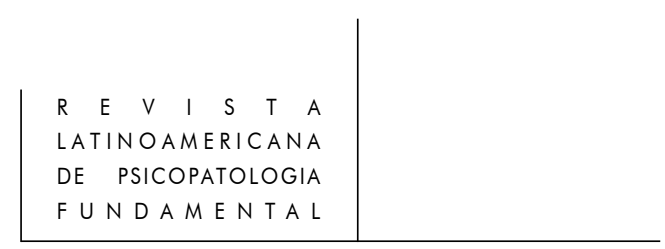

a chamada Psiquiatria Baseada em Evidências: as racionalidades de ordem epidemiológica e experimental vêm substituindo o olhar clínico voltado para o singular e para a experiência pessoal acumulada.

Os dois principais fóruns contemporâneos nos quais cada conduta terapêutica é validada ou refutada são: a) os grandes julgamentos clínicos (trials) e b) as chamadas "conferências de consenso".

Os primeiros são estudos, em geral multicêntricos, destinados a testar experimentalmente os resultados de uma certa prática clínica. Quanto às segundas, tratam-se de reuniões de especialistas de reconhecida competência em uma determinada área, que buscam chegar a uma conduta padronizada diante de certas situações clínicas específicas.

Um artigo publicado na revista The Lancet faz uma aproximação crítica desses procedimentos buscando colocar em evidência seus limites e seus perigos. Dessa forma, o autor mostra que os dados fornecidos por um trial clínico referem-se necessariamente a apenas alguns aspectos de uma certa constelação clínica, deixando de fora outros elementos decisivos: tratam-se de recortes parciais que não podem pretender a hegemonia das deliberações de ordem prática.

Além disso, ocorre o problema da aplicabilidade. Para que se formem os grupos homogêneos necessários ao método experimental, é necessária a aplicação de critérios muito restritivos de inclusão e de exclusão de pacientes nesses grupos a serem testados. Se, por um lado, os resultados são mais precisos no interior dos grupos assim constituídos, por outro, eles podem ser de baixa aplicabilidade nos casos concretos da prática cotidiana, mais rebeldes a definições estabelecidas a priori.

No extremo oposto, estudos menos rigorosos do ponto de vista da delimitação dos critérios de inclusão e de exclusão tendem a ser menos específicos, perdendo assim uma parte de seu valor.

Essa busca da autoridade impessoal da "evidência" cientificamente validada, não impede que a maior parte dos estudos que vão nessa direção sejam financiados pelas companhias farmacêuticas, as quais têm papel decisivo tanto no desenho do projeto de pesquisa quanto na análise dos dados.

No que concerne às reuniões de consenso, o artigo mostra que a escolha da chamada "melhor evidência" é necessariamente limitada e depende de interpretação de dados. Como cada participante tem interesse pessoal na sustentação de seus próprios pontos de vista diante das questões face às quais são especialistas, os resultados dos debates não podem deixar de portar as marcas dessa condição de base.

Por outro lado, o que dá autoridade ao resultado de uma reunião de consenso é que ela possa atingir a unanimidade entre seus membros. Contudo, tal unanimidade deve sempre levantar a suspeita de que tenha sido obtida à custa de compromissos e de simplificações. 
Dessa forma, o trabalho sustenta que o clínico deve interpretar ativamente os resultados desses procedimentos generalizantes à luz da particularidade da situação com a qual se defronta.

Resta a questão inquietante sobre o futuro das práticas clínicas: estará a ciência engendrando um "Big Brother" supra-humano que, com seu olhar onipresente, deliberará a partir de premissas gerais o que deve ou não ser feito em situações marcadas pelo ímpar e pelo singular?

"Caprices de souris transgéniques”

M. Enserink

La Recherche, 323: 36-37, septembre 1999

\section{Sobre a confiabilidade dos estudos transgênicos}

Um artigo publicado no mês de setembro passado em La Recherche mostra o grande cuidado que se deve ter com as conclusões das pesquisas genéticas no campo do comportamento. Pelo menos daquelas que se servem da observação do comportamento de animais geneticamente modificados, buscando com esse procedimento retirar inferências sobre o papel dos genes no comportamento humano.

O texto lembra que uma das técnicas mais utilizadas para se estabelecer as bases genéticas de um determinado comportamento consiste precisamente em se eliminar um gene suspeito em uma linhagem de ratos para, em seguida, submeter os animais a testes laboratoriais, controlando-se o comportamento em questão.

Contudo, ocorre, com freqüência, que a relação observada por certo grupo de pesquisadores entre um certo gene e um tipo de comportamento seja imediatamente contestada, ou mesmo desmentida, por um outro grupo, mesmo quando as condições experimentais são rigorosamente idênticas.

Um estudo conduzido nos Estados Unidos colocou em evidência a facilidade com que tais contradições podem aparecer.

Três grupos distintos de pesquisadores da genética do comportamento, trabalhando em cidades diferentes, aplicaram a mesma bateria de testes em cobaias da mesma linhagem, submetidas a condições ambientais praticamente idênticas.

Os procedimentos foram escrupulosamente uniformizados. O rigor foi tal que todos os três estudos foram iniciados entre 8h30 e 9h00 do dia 20 de abril de 1998. 
Cada um deles trabalhou com 128 ratos, com 77 dias de idade, provindos de mesmas linhagens geneticamente alteradas. As condições dos laboratórios, de alimentação, manipulação e repouso dos animais eram exatamente as mesmas.

Entretanto, apesar desse rigoroso pareamento, os resultados obtidos foram profundamente discordantes.

As diferenças expressaram-se sobretudo nos testes para avaliação do comportamento ansioso. Estes mostraram que os níveis de ansiedade de todas as linhagens foram mais baixos em Edmond, do que nos outros dois laboratórios.

Além disso, a linhagem da qual havia sido suprimido o gene do receptor de serotonina (implicado na ansiedade e na depressão) apresentou resultados totalmente diferentes nas três cidades.

Os pesquisadores explicaram tais variações em função de diferenças mínimas nas condições de realização do teste, tais como a composição química da água, o modo como as cobaias foram manipuladas e mesmo o aspecto físico e o odor dos cientistas e técnicos.

De qualquer forma coloca-se a necessidade, para a genética do comportamento, de uniformizar ainda mais rigorosamente seus testes e estabelecer um critério ainda mais restritivo para a publicação de resultados, aguardando que um mesmo experimento seja reproduzido no mesmo e em outros laboratórios antes da divulgação científica.

"Revisitando a psicopatologia: uma leitura da tese 'Psicopatologia da reação esquizofrênica' de A. L. Nobre de Melo”,

\section{A psicopatologia de Nobre de Melo revisitada}

A. L. Nobre Melo foi reconhecidamente um dos mais brilhantes psicopatólogos brasileiros. Seu famoso Tratado de Psiquiatria, publicado em 1979, tem sido uma referência maior na formação de inúmeras gerações de psiquiatras e psicopatólogos em nosso país e destaca-se por sua profundidade e erudição.

Contudo, excetuando-se aquela grande obra, o pensamento psicopatológico de Nobre Melo permanece relativamente desconhecido. 
Um artigo recentemente publicado no Jornal Brasileiro de Psiquiatria vem preencher parcialmente essa lacuna, apresentando algumas das linhas-mestras da tese de Nobre de Melo apresentada para o concurso de catedrático da disciplina de "Clínica Psiquiátrica” na Faculdade Fluminense de Medicina, no início dos anos 50. Intitulava-se "A psicopatologia da reação esquizofrênica".

A tese de Nobre de Melo divide-se em duas partes. A primeira analisa o surgimento, os limites e os desdobramentos da fenomenologia no campo psiquiátrico. Na segunda, o foco será o conceito de "reação", abordado sob uma perspectiva fenomenológica.

$\mathrm{O}$ artigo do JBP enfoca, sobretudo, a concepção fenomenológica de Nobre de Melo, deixando para um trabalho posterior a análise de seu conceito de "reação".

Partindo de uma breve contextualização histórica do surgimento da fenomenologia husserliana, o texto apresenta a visão de Nobre de Melo sobre alguns dos principais conceitos dessa disciplina, tais como: "Vivência" ou "Experiência vivida”, "Intencionalidade”, "Intuição”, "Redução fenomenológica”, “Compreensão”, "Explicação" e "Empatia”, "Processo" e "Desenvolvimento".

Além disso, o trabalho traz um quadro esquemático salientando, de forma bastante didática, as diferenças entre as perspectivas empírica e fenomenológica dos fenômenos psíquicos.

Apesar de um tanto sucinto, o artigo constitui uma interessante introdução à abordagem fenomenológica em psicopatologia e um convite instigante a que se conheça mais profundamente a obra de Nobre de Melo.

"Toward the identification of core psychopathological processes?" H-U. Wittchen, M. Höfler \& K. Merikangas Archives of General Psychiatry, vol. 56, n 10, October 1999

\section{Identificando processos psicopatológicos nucleares?}

Entre os grandes progressos obtidos pelos modernos sistemas diagnósticos operacionais no campo da epidemiologia psiquiátrica, uma descoberta chama particularmente a atenção: a enorme ocorrência simultânea de dois ou mais transtornos em um mesmo indivíduo - é o chamado fenômeno da comorbidade. 


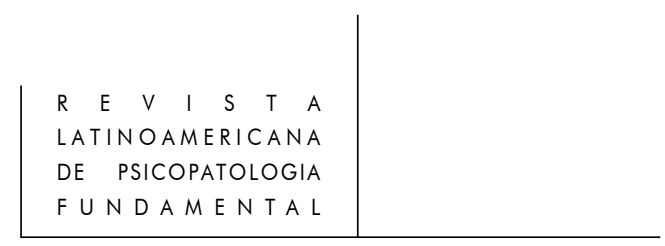

Estudos de comorbidade mostram que pessoas apresentando um determinado diagnóstico têm um risco aumentado de apresentar ao mesmo tempo um outro transtorno específico. A ligação entre esses transtornos não é fortuita, dando-se segundo padrões regulares de tipo e freqüência. Assim, por exemplo, indivíduos com o diagnóstico de Transtorno de Ansiedade Social têm maior risco de desenvolver depressão, pânico e abuso de álcool; ou, então, indivíduos com Transtorno de Pânico mostram maior chance de apresentar simultaneamente estados depressivos ou fóbicos.

Um artigo publicado no Archives of General Psychiatry de outubro/1999 retoma de forma crítica a questão, propondo uma abordagem nova e instigante para esse problema.

O autor propõe que as altas taxas de comorbidade observadas revelam, na verdade, que os sistemas diagnósticos são muito pródigos em categorias descritivas, mas perdem de vista as ligações profundas entre elas. Ele propõe, então, que certos transtornos mentais ocorrem juntos porque, de fato, são manifestações diversas de "um pequeno número de dimensões subjacentes ou processos psicopatológicos nucleares que podem ser mais significativos que os transtornos específicos” no que diz respeito à pesquisa sobre tratamento, prevenção e etiologia.

Utilizando uma vasta amostra epidemiológica e métodos estatísticos sofisticados, o autor sugere um modelo as ligações e a estrutura latente de 10 transtornos mentais mais comuns em uma amostra de adolescentes.

Sua proposta principal é a de que um modelo trifatorial, por ele nomeado de "miséria-ansiosa" e "medo" (representando diferentes facetas de um fator internalizante de ordem superior) e um fator externalizante difuso, é o que melhor explicaria as correlações entre os 10 transtornos.

Estes achados poderiam organizar a grande variação psicopatológica observada, em termos de fatores genéticos ou neurobiológicos comuns subjacentes.

Um artigo crítico publicado naquele mesmo número do Archives of General Psychiatry mostra as limitações do trabalho de Krueger a partir da análise dos dados utilizados, da abordagem estatística e da interpretação aplicada aos dados. Contudo, esse artigo termina por reiterar o valor da proposta de Krueger, no sentido de relativizar a abordagem sindrômica que faz o DSM-IV dos fenômenos psicopatológicos e da necessidade de se superar os artefatos introduzidos por esse recorte operacional em fatos psíquicos que certamente devem apresentar alguma coerência interna. 